\title{
Síntese de proteína microbiana e concentrações de uréia em vacas alimentadas com diferentes fontes de proteína ${ }^{1}$
}

\author{
Douglas dos Santos Pina ${ }^{2}$, Sebastião de Campos Valadares Filho ${ }^{3}$, Rilene Ferreira Diniz \\ Valadares $^{4}$, Edenio Detmann ${ }^{3}$, José Maurício de Souza Campos ${ }^{3}$, Mozart Alves Fonseca ${ }^{5}$, \\ Rafael Monteiro Araújo Teixeira ${ }^{2}$, André Soares de Oliveira ${ }^{2}$
}

\author{
${ }^{1}$ Parte da dissertação de Mestrado, parcialmente financiada pelo CNPq e pela FAPEMIG. \\ ${ }^{2}$ Doutorando em Zootecnia - UFV. Bolsista do CNPq. \\ ${ }^{3}$ Departamento de Zootecnia - UFV. Pesquisador do CNPq \\ ${ }^{4}$ Departamento de Veterinária - UFV. Pesquisadora do CNPq. \\ 5 Graduação em Zootecnia - UFV. Bolsista do PIBIC - CNPq.
}

RESUMO - Foram utilizadas 12 vacas Holandesas puras e mestiças, distribuídas em três quadrados latinos 4 x 4 , organizados de acordo com os dias em lactação, com o objetivo de avaliar o efeito de diferentes fontes protéicas sobre a síntese, a eficiência de síntese de proteína microbiana, a concentração de nitrogênio uréico no soro (NUS) e no leite (NUL), a concentração de nitrogênio amoniacal e o pH ruminal. Utilizou-se silagem de milho como volumoso, na proporção de $60 \%$ da $\mathrm{MS}$ total. Os concentrados foram constituídos de diferentes fontes protéicas (FS - farelo de soja; FA38 - farelo de algodão $38 \%$ PB; FA28 - farelo de algodão $28 \%$ PB e FSU - farelo de soja + 5\% de uréia/sulfato de amônia na MS do concentrado). As coletas spot de urina e de sangue foram realizadas no $18^{\circ}$ dia do período experimental 4 horas após o fornecimento da alimentação aos animais, no período da manhã. Não foram observadas diferenças entre as dietas para o volume urinário (V), a excreção total de derivados de purinas (PT), a síntese e a eficiência de síntese de PB microbiana, expressa em g de PB/kg de NDT consumido. As concentrações de NUS e NUL também não diferiram entre as dietas. As concentrações de NUS e NUL e a síntese de PB microbiana não foram influenciadas pelas diferentes fontes de proteína dietéticas, inclusive com a adição de uréia (5\% MS do concentrado).

Palavras-chave: digestibilidade, farelo de algodão, farelo de soja, nitrogênio uréico no leite, purinas, uréia

\section{Estimation of microbial protein synthesis and urea nitrogen metabolism in lactating dairy cows fed diets supplemented with different protein sources}

\begin{abstract}
Twelve Holstein lactating dairy cows were blocked by days in milk and randomly assigned to three replicated $4 \times 4$ Latin square to evaluate the effect of different protein sources on efficiency of microbial protein synthesis, concentration of serum (NUS) and milk (MUN) urea nitrogen, and ruminal metabolism. A basal corn silage diet (60\% of the total dry matter) was fed plus one of the following proteins sources (DM basis): soybean meal (SBM), cottonseed meal with $38 \%$ of crude protein (CSM38), cottonseed meal with $28 \%$ of crude protein (CSM28), or soybean meal plus $5 \%$ of urea/ammonium sulfate (SBMU). Each experimental period lasted 18 days with 11 days for diet adaptation and seven days for sample collection. Samples of urine and blood were obtained approximately four hours after the morning feeding on day 18 of each period. No significant differences among diets were observed for urinary volume (V), total purine derivatives excretion (PT), microbial CP synthesis and microbial efficiency, expressed in $\mathrm{g}$ of $\mathrm{CP} / \mathrm{kg}$ of TDN intake. In addition, concentration of both NUS and MUN also did not differ among diets. It can be concluded that NUS and MUN as well as microbial CP synthesis and efficiency were not affected by feeding different protein sources to lactating dairy cows.
\end{abstract}

Key Words: cottonseed meal, digestibility, milk urea nitrogen, purine, soybean meal, urea

\section{Introdução}

A função básica da produção de leite em animais especializados é converter fontes de alimentos não competitivas e de baixa qualidade em proteína de alta qualidade para o consumo humano. Freqüentemente, a quantidade e qualidade da proteína absorvida no intestino delgado podem limitar a produção de leite (Nousiainen et al., 2004).

$\mathrm{Na}$ prática, é difícil o ajuste da ingestão de proteína e energia. Perdas durante o armazenamento e a seleção da dieta pelo animal podem explicar porque os alimentos analisados não são completamente representativos dos ali- 
mentos realmente consumidos. Conseqüentemente, outros parâmetros facilmente mensuráveis podem ser de grande valor prático, como indicadores adicionais para a manipulação do suprimento de proteína (Hof et al., 1997).

Portanto, existe a necessidade de um diagnóstico para monitorar a adequação da nutrição protéica, oferecendo a oportunidade para otimizar a eficiência de utilização de nitrogênio para produção de proteína no leite e emissão de nitrogênio no ambiente. Altas concentrações de NUP (principal produto do metabolismo do nitrogênio em ruminantes) são indicativos de ineficiência na utilização do nitrogênio dietético (Nousiainen et al., 2004), todavia, a medição rotineira de NUP é difícil. Entretanto, é bem estabelecido que a uréia equilibra-se rapidamente com os fluidos corporais, inclusive o leite, o que pode resultar em alta correlação entre a concentração de NUL e NUP (Broderick \& Clayton, 1997). Como a concentração de NUL é determinada facilmente, pode ser usada como parâmetro para monitorar a nutrição protéica de vacas leiteiras (Schepers \& Meijer, 1998).

Na nutrição protéica de ruminantes, é fundamental a estimativa acurada da síntese de proteína microbiana ruminal e de sua contribuição em aminoácidos digestíveis para o animal. Esquemas de alimentação que alteram a produção de proteína microbiana afetam a quantidade e a qualidade da proteína que chega ao intestino delgado (Moscardini et al., 1998).

Segundo Ipharraguerre \& Clark (2005), a resposta de vacas à suplementação protéica é variável e uma proporção dessa variação em pesquisas é explicada pela variação na fonte de proteína na dieta controle, pela proporção, pela fonte de proteína não-degradada no rúmen na dieta experimental e pelo efeito da fonte de proteína sobre o fluxo ruminal de proteína microbiana, a qual é a melhor fonte de aminoácidos disponíveis para a síntese e produção de leite (Santos et al., 1998).

O fluxo de nitrogênio $(\mathrm{N})$ microbiano para o duodeno pode ser estimado a partir da excreção urinária de derivados de purina (principalmente alantoína e ácido úrico), sendo que a quantidade de ácido nucléico microbiano e, conseqüentemente, a síntese microbiana ruminal são proximamente correlacionadas à excreção urinária de derivados de purina (Moscardini et al., 1998). González-Ronquillo et al. (2004) demonstraram a utilidade dos derivados de purina urinários como potencial meio de detecção de alterações na síntese microbiana ruminal pelo menos com a mesma eficiência do método baseado na medição do fluxo duodenal pela técnica de dois indicadores.

Segundo Valadares et al. (1999), uma única amostra spot de urina de cada vaca em cada período experimental, utilizada para quantificação do volume urinário com base na excreção de creatinina, produziu aproximadamente a mesma estimativa da excreção urinária de derivados de purina e, conseqüentemente, da produção de $\mathrm{N}$ microbiano, quando comparada à coleta total de urina.

Conduziu-se esse trabalho com o objetivo de avaliar o efeito de diferentes fontes de proteína dietéticas sobre a síntese e a eficiência de síntese de proteína microbiana, calculadas a partir da excreção urinária de derivados de purina, a concentração de nitrogênio uréico no soro e no leite, a concentração de nitrogênio amoniacal e o pH ruminal.

\section{Material e Métodos}

O experimento foi realizado na Unidade de Ensino, Pesquisa e Extensão em Gado de Leite (UEPE-GL) do Departamento de Zootecnia da Universidade Federal de Viçosa (UFV), Viçosa-MG. Foram utilizados 12 animais da raça Holandesa, com peso médio de $550 \mathrm{~kg}$ e produção de $25 \mathrm{~kg}$ de leite/dia, distribuídos em três quadrados latinos (QL) $4 \times 4$, organizados de acordo com os dias em lactação, que variaram em média de 60 a 120 dias. A proporção dos ingredientes na mistura de concentrados e a composição dos concentrados, da silagem de milho e das dietas experimentais são apresentadas nas Tabelas 1, 2 e 3, respectivamente.

Foram avaliadas quatro dietas constituídas de diferentes fontes protéicas: FS (farelo de soja); FA38 (farelo de algodão com $38 \%$ de PB); FA2 (farelo de algodão com $28 \%$

Tabela 1 - Proporção dos ingredientes nos concentrados, com base na MS

Table 1 - Ingredient composition of the concentrates, dry matter basis

\begin{tabular}{|c|c|c|c|c|}
\hline \multirow[t]{2}{*}{$\begin{array}{l}\text { Ingrediente } \\
\text { Ingredient }\end{array}$} & \multicolumn{4}{|c|}{$\begin{array}{l}\text { Concentrado } \\
\text { Concentrate }\end{array}$} \\
\hline & $\begin{array}{c}\text { FS } \\
S B M\end{array}$ & $\begin{array}{l}\text { FA } 38 \\
\text { CSM } 38\end{array}$ & $\begin{array}{l}\text { FA } 28 \\
\text { CSM } 28\end{array}$ & $\begin{array}{l}\text { FSU } \\
S B M U\end{array}$ \\
\hline $\begin{array}{l}\text { Fubá de milho } \\
\text { Ground corn }\end{array}$ & 43,67 & 29,81 & 15,42 & 62,01 \\
\hline $\begin{array}{l}\text { Farelo de soja } \\
\text { Soybean meal }\end{array}$ & 41,61 & - & 14,39 & 19,77 \\
\hline $\begin{array}{l}\text { Farelo de trigo } \\
\text { Wheat meal }\end{array}$ & 10,00 & 10,00 & 10,00 & 10,00 \\
\hline $\begin{array}{l}\text { Farelo de algodão } 38 \\
\text { Cottonseed meal } 38\end{array}$ & - & 55,47 & - & - \\
\hline $\begin{array}{l}\text { Farelo algodão } 28 \\
\text { Cottonseed meal } 28\end{array}$ & - & - & 55,47 & - \\
\hline $\begin{array}{l}\text { Uréia/SA } \\
\text { UreaAS }\end{array}$ & 1,50 & 1,50 & 1,50 & 5,00 \\
\hline $\begin{array}{l}\text { Mistura mineral } \\
\text { Mineral mix }\end{array}$ & 3,22 & 3,22 & 3,22 & 3,22 \\
\hline
\end{tabular}

$\mathrm{FS}=$ farelo de soja; FA38 = farelo de algodão com 38\% de PB; FA28 = farelo de algodão com $28 \%$ de PB e FSU = FS mais uréia ( $S B M=$ soybean meal; $C S M 38$ $=$ cottonseed meal with $38 \% C P ; C S M 28=$ cottonseed meal with $28 \% C P$ and $S B M U=S B M$ plus urea). 
Tabela 2 - Teores médios de MS, MO, PB, proteína degradada no rúmen (PDR), proteína não-degradada no rúmen (PNDR), compostos nitrogenados não-protéicos (NNP), NIDA, EE, FDN, FDNcp, CNF, LIG e NDT obtidos nos concentrados e na silagem de milho

Table 2 - $\quad$ Average contents of DM, OM, CP, RDP, RUP, NPN, ADIN, EE, NDF, NDFap, NFC, lignin, and TDN of concentrates and corn silage

\begin{tabular}{|c|c|c|c|c|c|}
\hline \multirow[t]{2}{*}{ Item } & \multicolumn{4}{|c|}{$\begin{array}{c}\text { Concentrado } \\
\text { Concentrate }\end{array}$} & \multirow[t]{2}{*}{$\begin{array}{c}\text { Silagem } \\
\text { Silage }\end{array}$} \\
\hline & $\begin{array}{c}\text { FS } \\
S B M\end{array}$ & $\begin{array}{l}\text { FA } 38 \\
\text { CSM } 38\end{array}$ & $\begin{array}{l}\text { FA28 } \\
\text { CSM } 28\end{array}$ & $\begin{array}{c}\text { FSU } \\
S B M U\end{array}$ & \\
\hline $\mathrm{MS}(D M, \%)$ & 87,94 & 88,66 & 89,02 & 88,29 & 29,76 \\
\hline MO $(O M)^{1}$ & 92,79 & 92,00 & 92,15 & 93,94 & 95,19 \\
\hline $\mathrm{PB}(C P)^{1}$ & 28,89 & 30,53 & 28,73 & 28,67 & 5,26 \\
\hline $\operatorname{PDR}(R D P)^{1}$ & 18,34 & 19,55 & 20,32 & 21,95 & 4,45 \\
\hline $\operatorname{PNDR}(R U P)^{1}$ & 10,55 & 10,99 & 8,41 & 6,71 & 0,81 \\
\hline $\mathrm{NNP}(N P N)^{2}$ & 21,53 & 22,60 & 24,10 & 48,85 & 44,51 \\
\hline NIDA $(A D I N)^{2}$ & 0,74 & 0,44 & 0,83 & 0,69 & 2,28 \\
\hline $\mathrm{EE}^{1}$ & 2,42 & 2,91 & 1,54 & 2,89 & 2,15 \\
\hline FDN $(N D F)^{1}$ & 16,54 & 29,97 & 38,74 & 16,16 & 62,34 \\
\hline FDNcp $(\text { NDFap })^{1}$ & 10,89 & 27,68 & 33,31 & 11,60 & 58,54 \\
\hline $\mathrm{CNF}(N F C)^{1}$ & 47,19 & 30,84 & 25,40 & 53,72 & 25,43 \\
\hline $\mathrm{LIG}^{1}$ & 1,30 & 6,11 & 7,82 & 1,22 & 3,2 \\
\hline $\mathrm{NDT}_{\text {est }}\left(T D N_{e s t}\right)^{1,3}$ & 70,26 & 65,78 & 60,19 & 75,43 & 62,88 \\
\hline
\end{tabular}

$1 \% \mathrm{MS} ; 2$ \% do $\mathrm{N}$ total; ${ }^{3}$ estimado pelas equações do NRC (2001) para consumo de três vezes a manteça. $F S=$ farelo de soja; FA38 = farelo de algodão com $38 \%$ de PB; FA28 = farelo de algodão com $28 \%$ de PB e FSU $=\mathrm{FS}+$ uréia $\left({ }^{1} \% D M ;{ }^{2} \%\right.$ total $\mathrm{N} ;{ }^{3}$ estimated by NRC (2001) assuming an intake of three times the maintenance. $S B M=$ soybean meal; $C S M 38=$ cottonseed meal with $38 \% C P$ CSM28 $=$ cottonseed meal with $28 \% C P$ and SBMU = SBM plus urea).

Tabela 3 - Teores médios de MS, MO, PB, PDR, PNDR, NNP, NIDA, EE, FDN, FDNcp, CNF, LIG e NDT obtidos nas dietas experimentais

Table 3 - $\quad$ Average contents of DM, OM, CP, RDP, RUP, NPN, ADIN, EE, NDF, NDFap, NFC, lignin and TDN estimated for the four experimental diets

\begin{tabular}{|c|c|c|c|c|}
\hline \multirow[t]{2}{*}{$\begin{array}{l}\text { Item } \\
\text { Item }\end{array}$} & \multicolumn{4}{|c|}{$\begin{array}{c}\text { Dieta } \\
\text { Diet }\end{array}$} \\
\hline & FS & $\begin{array}{l}\text { FA38 } \\
\text { CSM } 38\end{array}$ & $\begin{array}{l}\text { FA28 } \\
\text { CSM28 }\end{array}$ & $\begin{array}{c}\text { FSU } \\
S B M U\end{array}$ \\
\hline MS (DM, \%) & 53,03 & 53,32 & 53,46 & 53,17 \\
\hline MO $(O M)^{1}$ & 94,23 & 93,91 & 93,98 & 94,69 \\
\hline $\mathrm{PB}(C P)^{1}$ & 14,71 & 15,37 & 14,65 & 14,62 \\
\hline $\operatorname{PDR}(R D P)^{1}$ & 10,01 & 10,49 & 10,80 & 11,45 \\
\hline PNDR $(R U P)^{1}$ & 4,71 & 4,88 & 3,85 & 3,17 \\
\hline NNP $(N P N)^{2}$ & 35,32 & 35,75 & 36,35 & 46,25 \\
\hline NIDA $(A D I N)^{2}$ & 1,66 & 1,54 & 1,70 & 1,64 \\
\hline $\mathrm{EE}^{1}$ & 2,26 & 2,45 & 1,91 & 2,45 \\
\hline $\operatorname{FDN}(N D F)^{1}$ & 44,02 & 49,39 & 52,90 & 43,87 \\
\hline FDNcp $(\text { NDFap })^{1}$ & 39,48 & 46,20 & 48,45 & 39,76 \\
\hline $\mathrm{CNF}(N F C)^{1}$ & 34,13 & 27,59 & 25,42 & 36,75 \\
\hline $\mathrm{LIG}^{1}$ & 2,44 & 4,36 & 5,05 & 2,41 \\
\hline $\mathrm{NDT}_{\text {est }}\left(T D N_{\text {est }}\right)^{1,3}$ & 65,83 & 64,04 & 61,80 & 67,90 \\
\hline
\end{tabular}

$1 \%$ MS; $2 \%$ do $\mathrm{N}$ total; ${ }^{3}$ estimado pelas equações do NRC (2001), para um consumo de três vezes a manteça. $\mathrm{FS}=$ farelo de soja; $F A 38=$ farelo de algodão com $38 \%$ de PB; FA28 = farelo de algodão com $28 \%$ de PB e FSU $=\mathrm{FS}+$ uréia ( $1 \% D M: 2 \%$ total $N \cdot{ }^{3}$ estimated by NRC (2001) assuming an intake of three times the maintenance. SBM = soybean meal; CSM38 = cottonseed meal with $38 \%$ $C P ; C S M 28=$ cottonseed meal with $28 \% C P$ and $S B M U=S B M$ plus urea). de PB) e FSU (farelo de soja com 5\% de uréia/sulfato de amônia). Utilizou-se silagem de milho como volumoso, na proporção de $60 \%$ da MS total da dieta. Os concentrados foram formulados de forma a serem isoprotéicos, com aproximadamente $26 \%$ de PB na matéria natural, e as dietas continham $15,5 \%$ de $\mathrm{PB}$ na MS, conforme proposto por Pereira (2003). À exceção da dieta FSU, todas as demais foram adicionadas de 1,5\% de uréia/sulfato de amônia, com base da MS total dos concentrados. A dieta FA28 foi constituída da mesma proporção de farelo de algodão da dieta FA38 e, conseqüentemente, necessitou da adição de farelo de soja.

O experimento foi constituído de quatro períodos de 18 dias, sendo os 11 primeiros destinados à adaptação dos animais às dietas e o restante à coleta de dados. Os animais foram alojados em baias individuais providas de cocho e bebedouro automático e receberam alimentação na forma de mistura completa, ad libitum, duas vezes ao dia, após as ordenhas da manhã e da tarde, de modo a permitir 5 a $10 \%$ de sobras em relação à matéria natural do alimento oferecido.

As ordenhas foram realizadas diariamente duas vezes ao dia (6 e 16h) e, no 15ํㅡ dia do período de coleta, efetuaramse amostras individuais em cada ordenha, que, posteriormente, formaram uma amostra composta proporcional às produções dos períodos da manhã e da tarde, conforme recomendado por Broderick \& Clayton (1997). A amostra composta foi desproteinizada via filtração em papel de filtro (mistura de $10 \mathrm{~mL}$ de leite com $5 \mathrm{~mL}$ de ácido tricloroacético a $25 \%$ ) por aproximadamente 30 minutos e congelada a $-20^{\circ} \mathrm{C}$, para posteriores análises de uréia e alantoína.

No $18^{\circ}$ dia do período experimental, foi coletada, 4 horas após o fornecimento do alimento, uma amostra spot de urina de cada animal. Alíquotas de $10 \mathrm{~mL}$ de urina foram diluídas em $40 \mathrm{~mL}$ de ácido sulfúrico $0,036 \mathrm{~N}$ e congeladas a $-20^{\circ} \mathrm{C}$ para análises e determinação dos derivados de purinas (ácido úrico e alantoína), creatinina e uréia, conforme descrito por Valadares et al. (1997).

No mesmo dia e mesmo horário, foram coletadas amostra individuais de sangue por meio de punção na artéria coccígea com um coletor contendo acelerador de coagulação. Essas amostras foram centrifugadas a $5.000 \mathrm{rpm}$ por 15 minutos e o plasma foi congelado a $-20^{\circ} \mathrm{C}$ para posterior determinação dos teores de uréia.

A uréia foi quantificada na amostra spot de urina diluída, no plasma e no leite desproteinizado. A creatinina e o ácido úrico foram determinados na urina diluída, utilizando-se kits comercias (Labtest Diagnóstica S.A.), e o N-uréico foi obtido multiplicando-se o teor de uréia no soro e no leite por 0,466 . 
As análises de alantoína na urina spot diluída e no leite desproteinizado foram feitas pelo método colorimétrico, conforme método de Fujihara et al. (1987), descrito por Chen \& Gomes (1992).

O volume urinário médio diário foi obtido dividindo-se a excreção total de creatinina (concentração de creatinina em $\mathrm{mg} / \mathrm{kg}$ de PC multiplicada pelo peso corporal) pela concentração de creatinina na amostra spot de urina, utilizando-se o valor de $24,4 \mathrm{mg} / \mathrm{kg}$ de PC de creatinina para estimativa do volume urinário. Esse valor foi a média encontrada por Pereira (2003) para vacas nos terços inicial e médio da lactação. A excreção total de derivados de purina foi calculada pela soma das quantidades de alantoína e ácido úrico excretadas na urina e das quantidades de alantoína secretadas no leite, expressas em mmol/dia. $\mathrm{O}$ balanço de nitrogênio foi obtido subtraindo-se o nitrogênio excretado nas fezes, na urina e no leite do total de nitrogênio consumido.

As purinas absorvidas (X, mmol/dia) foram estimadas a partir da excreção de derivados de purinas (Y, mmol/dia), por meio da equação $\mathrm{Y}=0,85 \mathrm{X}+0,385 \mathrm{PV}^{0,75}$, em que 0,85 é a recuperação das purinas absorvidas como derivados de purina e $0,385 \mathrm{PV}^{0,75}$ é a contribuição endógena para excreção de purinas (Verbic et al., 1990). A síntese ruminal de compostos nitrogenados (Y,gN/dia) foi calculada com base nas purinas absorvidas $(\mathrm{X}, \mathrm{mmol} / \mathrm{dia})$ utilizando-se a equação de Chen \& Gomes, (1992): $\mathrm{Y}=70 \mathrm{X} /(0,83$ x 0,134 x 1000), em que 70 é o conteúdo de $\mathrm{N}$ nas purinas ( $\mathrm{mgN} / \mathrm{mmol}) ; 0,134$, a relação N-purina/N-total nas bactérias (Valadares et al., 1999); e 0,83, a digestibilidade das purinas microbianas.

Os valores de $\mathrm{pH}$ e $\mathrm{N}-\mathrm{NH}_{3}$ foram obtidos de três animais fistulados no rúmen, resultando em 12 observações para cada uma das variáveis, provenientes de quatro tratamentos e três repetições. Esses dados não foram analisados em nenhum delineamento estatístico, de modo que a média de seus valores foi acompanhada somente do erro-padrão da média associado a cada uma das estimativas.

As análises estatísticas foram realizadas segundo delineamento em quadrado latino, aplicando-se o teste de Dunnett a 5\% de probabilidade, no qual as dietas FA38, FA28 e FSU foram comparadas à dieta controle (FS) para todas as variáveis analisadas.

\section{Resultados e Discussão}

A produção de leite $(23,85 ; 23,76 ; 22,69$ e 23,42$)$ não foi significativamente diferente entre as dietas FS, FA38, FA28 e FSU, respectivamente, mas a produção (g/dia) e a porcentagem de PB (\%) no leite foram significativamente menores para a dieta FA38 $\left(2,98^{*}\right.$ e $\left.702,36^{*}\right)$ em relação à FS $(3,19$ e 756,92) (Pina, 2005).

As médias diárias para o volume urinário $(\mathrm{V})$ estimado, as excreções urinárias de uréia, alantoína e ácido úrico, a secreção láctea de alantoína, a excreção total de derivados de purinas e a estimativa de síntese de proteína microbiana e sua eficiência, em termos de NDT consumido, podem ser observadas na Tabela 4.

Não foi encontrada diferença $(\mathrm{P}>0,05)$ para as estimativas do volume urinário. Não houve influência das diferentes fontes protéicas da dieta sobre a concentração de creatinina na urina. Pereira (2003) não observou efeito dos níveis crescentes de PB dietética sobre a excreção de creatinina urinária. Oliveira et al. (2001) também relataram ausência de significância de níveis crescentes de compostos nitrogenados não-protéicos dietéticos sobre a excreção urinária de creatinina $(23,41 \mathrm{mg} / \mathrm{kg}$ PC), semelhante ao valor

Tabela 4 - Médias diárias para volume urinário (V), excreções urinárias de uréia $(U)$, alantoína (ALA) e ácido úrico (ACU), secreção de alantoína no leite (ALL), purinas totais (PT) e estimativas da síntese diária de compostos nitrogenados microbianos (NMic) e de proteína bruta microbiana (PBMic) e eficiência microbiana (EMic) obtidas com as diferentes dietas

Table 4 - Average daily urinary volume (V), urinary excretions of urea $(U)$, allantoin (ALA) and uric acid (UA), allantoin secretion in milk (ALM), total purines (TP) and estimated daily synthesis of microbial nitrogen (NMic), microbial crude protein (CPMic) and microbial efficiency (MEf) of diets supplemented with different protein sources

\begin{tabular}{|c|c|c|c|c|c|}
\hline \multirow[t]{2}{*}{ Item } & \multicolumn{4}{|c|}{$\begin{array}{l}\text { Dieta } \\
\text { Diet }\end{array}$} & \multirow[t]{2}{*}{ CV (\%) } \\
\hline & $\begin{array}{l}\mathrm{FS} \\
S B M\end{array}$ & $\begin{array}{l}\text { FA38 } \\
\text { CSM38 }\end{array}$ & $\begin{array}{l}\text { FA } 28 \\
\text { CSM } 28\end{array}$ & $\begin{array}{l}\text { FSU } \\
S B M U\end{array}$ & \\
\hline $\mathrm{V}(\mathrm{L})$ & 14,37 & 14,29 & 14,12 & 12,93 & 20,90 \\
\hline $\mathrm{U}(\mathrm{mg} / \mathrm{kg} \mathrm{PV})$ & 577,85 & 507,17 & $663,21 *$ & * 598,96 & 11,98 \\
\hline $\begin{array}{l}\text { ALA (mmol/dia) } \\
A L A\end{array}$ & 362,21 & 326,25 & 377,45 & 349,36 & 13,80 \\
\hline $\begin{array}{l}\mathrm{ACU}(\mathrm{mmol} / \mathrm{dia}) \\
U A\end{array}$ & 43,34 & 39,84 & 37,16 & 42,16 & 30,57 \\
\hline $\begin{array}{l}\text { ALL (mmol/dia) } \\
A L M\end{array}$ & 3,23 & 2,78 & 2,64 & 3,09 & 39,60 \\
\hline $\begin{array}{l}\mathrm{PT} \quad(\mathrm{mmol}) \\
T P\end{array}$ & 408,77 & 368,88 & 417,26 & 394,62 & 13,71 \\
\hline $\begin{array}{l}\text { NMic (g/dia) } \\
\text { NMic }\end{array}$ & 268,99 & 238,86 & 274,93 & 258,64 & 15,50 \\
\hline $\begin{array}{l}\text { PBMic (g/dia) } \\
\text { CPMic }\end{array}$ & 1681,15 & 1492,86 & 1718,29 & 1616,51 & 15,50 \\
\hline $\begin{array}{l}\text { EMic } \\
(\mathrm{g} \mathrm{PB} / \mathrm{kgNDT}) \\
M E f\end{array}$ & 122,98 & 118,51 & 136,71 & 120,74 & 16,25 \\
\hline
\end{tabular}

${ }^{1}$ Médias na linha seguidas por $\left({ }^{*}\right)$ diferem do tratamento controle (FS) pelo teste de Dunnett $(P<0,05) ; C V=$ coeficiente de variação. $F S=$ farelo de soja; FA38 = farelo de algodão com 38\% de PB; FA28 = farelo de algodão com $28 \%$ de PB e FSU = FS + uréia (Mean in the same rows with (*) differ from the control diet ( $S B M)$ by Dunnett test $(P<0.05), C V=$ coefficient of variation. $S B M=$ soybean meal; $C S M 38=$ cottonseed meal with $38 \%$ CP; CSM $28=$ cottonseed meal with $28 \% C P$ and $S B M U=S B M$ plus urea). 
de $23,6 \mathrm{mg} / \mathrm{kg}$ PC observado por Silva et al. (2001). Chizzotti (2004) avaliaram a excreção de creatinina em vacas com diferentes níveis de produção de leite (média 32,60; 18,54 e $5,88 \mathrm{~kg} /$ dia) e não observaram variação significativa na excreção urinária de creatinina, obtendo o valor médio de $24,04 \mathrm{mg} / \mathrm{kg}$ de PC.

A excreção urinária de uréia ( $\mathrm{mg} / \mathrm{kg}$ PC) foi significativamente $(\mathrm{P}<0,05)$ maior para a dieta $\mathrm{FA} 28$ em relação à controle (FS), provavelmente em razão do baixo teor de CNF dessa dieta, que foi bastante inferior aos 35\% CNF sugeridos por Valadares et al. (1999) para maximizar a utilização dos compostos nitrogenados não-protéicos dietéticos. Oliveira et al. (2001) relataram aumento linear significativo na excreção urinária de uréia com o fornecimento de níveis crescentes de NNP na dieta. Esses autores obtiveram valor máximo de $374,46 \mathrm{mg} / \mathrm{kg}$ PC, inferior aos de 577,85; 507,17; 663,21 e $598,96 \mathrm{mg} / \mathrm{kg}$ PC registrados nesse experimento para as dietas FS, FA38, FA28 e FSU, respectivamente.

Os valores de ALA, ACU, ALL, PT, PBMic e EMic não foram afetados significativamente $(\mathrm{P}>0,05)$ pelas diferentes fontes de proteína dietéticas. Pereira (2003) não observou efeitos significativos dos níveis protéicos dietéticos sobre a excreção de alantoína na urina de vacas no terço inicial da lactação e encontraram valor de $303,45 \mathrm{mmol} /$ dia com a dieta de $15,5 \%$ de $\mathrm{PB}$ na MS, um pouco inferior à média (353,82 $\mathrm{mmol} /$ dia) estimada neste trabalho.

Valores mais altos de ALA (369 a $535 \mathrm{mmol} / \mathrm{dia}$ ) foram relatados por Valadares et al. (1999), em estudo com vacas de alta produção ( $40 \pm 7 \mathrm{~L}$ de leite/dia). As estimativas de ACU neste experimento apresentaram tendência semelhante às de ALA e não foram influenciadas $(\mathrm{P}>0,05)$ pelas diferentes fontes de proteína na dieta.

A secreção de alantoína láctea (ALL) não foi afetada $(\mathrm{P}>0,05)$ pelas diferentes fontes protéicas. Foram observados valores de 3,23; 2,78; 2,64 e 3,09 para as dietas contendo FS, FA38, FA28 e FSU, respectivamente, que se encontram na faixa $(4,26$ e $2,78 \mathrm{mmol} /$ dia $)$ descrita por GonzálesRonquillo et al. (2003) para animais no início e final da lactação com produção média de 27 e $17 \mathrm{~kg}$ de leite/dia, respectivamente. Na maioria dos trabalhos citados na literatura, a excreção de derivados de purina esteve positivamente correlacionada à produção de leite, provavelmente porque as mudanças na síntese microbiana ruminal estão associadas a alterações nas quantidades de proteína e energia fornecidas ao animal hospedeiro, conseqüentemente aumentando ou diminuindo o aporte de nutrientes para produção de leite. A correlação entre a produção de leite e ALL pode certamente limitar o uso da alantoína ou derivados lácteos de purina como índice para a predição do suprimento de proteína microbiana em vacas lactantes (Gonzáles-Ronquillo et al., 2003). Por isso, a secreção de derivados de purinas no leite não pode ser considerada um substituto para a excreção de derivados de purina na urina, como índice para estimativa da síntese de proteína microbiana ruminal (González-Roquillo, et al. 2004).

Pereira (2003) não encontrou efeito significativo dos níveis crescentes de PB dietéticos sobre a ALL em vacas nos terços inicial e médio da lactação. Valadares et al. (1999) constataram aumento linear significativo (de 18,7 para $28,6 \mathrm{mmol} / \mathrm{dia})$ na ALL ao elevarem de 20 para $65 \%$ a participação de concentrado na MS da dieta (à base de silagem de alfafa). Esses autores observaram relação média de 4,2 a 5,7\% entre ALL e excreção total de derivados de purinas, semelhante às relatadas por Silva et al. (2001), de 4,5\%, Oliveira et al. (2001), de 3,37 a 4,49\%, e Chen \& Gomes (1992), de 5\%. Neste experimento, a relação média encontrada foi de $0,75 \%$, dentro da amplitude de variação observada por Gieseck et al. (1994), de 0,6 a 2,4\%, e por Gonda \& Lindenberg (1997), de 0,63 a 1,34\%.

Apesar da ausência de efeito $(\mathrm{P}>0,05)$ das diferentes fontes protéicas sobre PBMic e EMic, houve diferença numérica para essas variáveis, que apresentaram valores superiores para a dieta FA28 e inferiores para FA38. A dieta FSU foi a que mais se aproximou dos valores encontrados para a dieta controle (FS). O menor valor numérico para a PBMic observado para a dieta contendo FA38 pode explicar a menor eficiência de utilização de nitrogênio $(0,248$ e $\left.0,217^{*}\right)$ e o mais baixo teor $\left(3,19\right.$ e $\left.2,98^{*}\right)$ e produção de PB (756,92 e 702,36*) no leite (Pina, 2005).Segundo Santos et al. (1998), a proteína microbiana é a melhor e o farelo de soja (bom perfil de aminoácidos), a segunda melhor fonte de aminoácidos disponíveis para a síntese e produção de leite.

A ausência de farelo de soja na dieta FA38, associada ao menor teor de CNF nessa dieta, proporcionado pela menor inclusão de fubá de milho (Tabela 1), pode ter sido a causa da menor produção numérica de PB microbiana. Em compilação de dados provenientes de 11 experimentos com vacas lactantes, Valadares Filho \& Chizzotti (2005) encontraram eficiência microbiana média de 118,3 g de PBMic/kg de NDT, com desvio-padrão de 15,53. A média encontrada neste experimento (124,73 g de PBMic/kg de NDT), portanto, encontra-se neste intervalo.

Os valores de NUL e NUS e o balanço de compostos nitrogenados são descritos na Tabela 5 .

Os valores de NUL e NUS não foram afetados $(\mathrm{P}>0,05)$ pelas fontes protéicas. Valores mais elevados foram obtidos para a concentração de NUS em relação à de NUL, porém, alguns autores citam valores de NUL superiores aos de NUS 
Tabela 5 - Médias diárias para as concentrações de NUS e NUL, compostos nitrogenados totais no leite (NTL) e o balanço de compostos nitrogenados (BN) obtidas com diferentes fontes de proteína na dieta

Table 5 - $\quad$ Average urea nitrogen concentration of serum (NUS) and milk (MUN), total milk nitrogen (TMN) and nitrogen balance (NB) of diets supplemented with different protein sources

\begin{tabular}{lccccc}
\hline \multirow{2}{*}{ Item } & \multicolumn{5}{c}{$\begin{array}{c}\text { Dieta } \\
\text { Diet }\end{array}$} \\
\cline { 2 - 5 } & FS & FA38 & FA28 & FSU \\
& SBM & CSM38 & CSM28 & SBMU & \\
\hline NUS (mg/dL) & 21,82 & 18,24 & 22,60 & 22,97 & 16,50 \\
NUL (mg/dL) & 15,26 & 12,45 & 12,65 & 15,13 & 21,71 \\
$M U N$ & & & & & \\
NUL (g/dia) & 3,55 & 2,92 & 2,91 & 3,53 & 25,03 \\
$M U N$ & & & & & \\
NTL (g/dia) & 118,63 & $109,99 *$ & $108,68 *$ & 114,77 & 6,38 \\
TMN & & & & & \\
BN (g/dia) & 30,75 & $60,72 *$ & $5,09 *$ & 27,63 & 47,30 \\
NB & & & & & \\
\hline
\end{tabular}

${ }^{1}$ Médias na linha seguidas por ${ }^{*}$ ) diferem do tratamento controle $(\mathrm{FS})$ pelo teste Dunnett $(P<0,05) ; C V=$ coeficiente de variação. $F S=$ farelo de soja; FA38 = farelo de algodão com $38 \%$ de PB; FA28 = farelo de algodão com $28 \%$ de PB e FSU = FS + uréia (Mean in the same rows with $\left(^{*}\right)$ differ from the control $\operatorname{diet}(S B M)$ by Dunnett test $(P<0.05), C V=$ coefficient of variation. $S B M=$ soybean meal; CSM38 = cottonseed meal with $38 \%$ CP; CSM 28 = cottonseed meal with $28 \% C P$ and $S B M U=S B M$ plus urea)

(Pereira, 2003; Imaizumi et al., 2002; Oliveira et al., 2001; Silva et al., 2001).

Essas diferenças nas concentrações de NUS e NUL podem ser explicadas pelo fato de o NUL ser uma medida que reflete o conteúdo médio de uréia nos períodos matutino e vespertino, enquanto a concentração de NUS afere o conteúdo de uréia no soro somente no momento em que a amostra foi coletada. Segundo Gustafsson \& Palmquist (1993), o NUS e a concentração de $\mathrm{N}-\mathrm{NH}_{3}$ no rúmen variam com o consumo de alimentos, de modo que os picos diários de concentração de NUS ocorrem aproximadamente 1 a 2 horas após o pico de $\mathrm{N}_{-} \mathrm{NH}_{3}$ no rúmen ou 2 a 4 horas após a alimentação.

A maior concentração de $\mathrm{N}-\mathrm{NH}_{3}$ ruminal com a dieta FSU ocorreu 4 horas após a alimentação. Esse atraso em relação à dieta controle (FS) pode explicar os valores próximos de NUS $(21,82$ e $22,97 \mathrm{mg} / \mathrm{dL})$ encontrados para as dietas FS e FSU, respectivamente, visto que os picos diários de concentração de NUS ocorrem aproximadamente 1 a 2 horas após o pico de $\mathrm{N}_{-} \mathrm{NH}_{3}$ no rúmen (Gustafsson \& Palmquist, 1993), observando-se as maiores concentrações de N-NH $\mathrm{NH}_{3}$ ruminal para as dietas FS, FA38, FA28 aproximadamente 2 horas após a alimentação (Figura 1).

Comparando as dietas FA38 e FA28 à dieta controle (FS), não foram observados efeitos das diferentes fontes protéicas dietéticas sobre as concentrações de NUS e NUL.
Esses resultados diferem dos obtidos por Imaizumi et al. (2002), que observaram efeitos linear e quadrático significativos para a concentração de NUL e quadrático para a concentração de NUS em vacas alimentadas com diferentes níveis $(0,50$ e $100 \%)$ de farelo de algodão em substituição ao farelo de soja. No entanto, corrobora as observações de Mena et al. (2004), que não encontraram efeito $(P>0,05)$ nos níveis de NUL (12,33 e 13,08 mg/dL) em dietas à base de farelo de algodão e farelo de soja, respectivamente. Também Blackwelder et al. (1998) não notaram diferença significativa nos níveis de NUS (17,5 e 17,1 mg/dL) de vacas alimentadas com dietas à base de farelo de soja e de algodão.

Segundo Butler et al. (1995), a variação horária de NUL segue o mesmo padrão de nitrogênio uréico no soro (NUS), podendo ser um parâmetro útil para avaliar a utilização da proteína em relação à sua ingestão. Esses autores testaram amostras obtidas em 19 rebanhos leiteiros de alta produtividade e obtiveram valor médio de NUL de 17,7 mg/dL (14,4 a 20,2 mg/dL). Hutjens \& Barmore (1995), citados por Broderick (1995), sugeriram que variação de 12 a $17 \mathrm{mg} / \mathrm{dL}$ de NUL indica ótimo balanceamento de proteína degradada e energia fermentada no rúmen. Valores de 10 a $16 \mathrm{mg} / \mathrm{dL}$, dependendo da produção de leite, foram sugeridos por Jonker et al. (1999), que recomendaram a utilização de NUL para avaliar a excreção de nitrogênio em vacas de leite. Pereira (2003) citou que, para vacas nos terços inicial e médio da lactação consumindo dietas com 15,5 e 12,3\% de PB na MS total, respectivamente, concentrações de NUP de 17,4 (inicial) e $10,3 \mathrm{mg} / \mathrm{dL}$ (medio) seriam os limites de uréia plasmática, podendo ser consideradas índices de condição nutricional com menores perdas ou utilização eficiente dos compostos nitrogenados dietéticos para produção de leite.

Os valores de NUL $(15,26 ; 12,45 ; 12,65$ e $15,13 \mathrm{mg} / \mathrm{dL})$ observados para todas as dietas desse experimento encontram-se na faixa (10 a $17 \mathrm{mg} / \mathrm{dL}$ ) determinada pela maioria dos pesquisadores como a que resulta em melhor eficiência de utilização do nitrogênio dietético.

O balanço de compostos nitrogenados não diferiu $(\mathrm{P}>0,05)$ entre as dietas FSU e controle (FS), mas diferiu $(\mathrm{P}<0,05)$ entre FA38 e FA28, observando-se a maior retenção de nitrogênio dietético com a dieta contendo FA38 e a menor, com a dieta contendo FA28. Esses dados confirmam a maior excreção de nitrogênio uréico na urina $(\mathrm{mg} / \mathrm{kgPV})$ para a dieta FA $28(663,21 *$ e 577,85) e a menor excreção numérica para a dieta FA38 $(507,17$ e 577,85) em relação à controle (FS) (Tabela 4).

Os dados de $\mathrm{pH}$ e concentração de $\mathrm{N}-\mathrm{NH}_{3}$ ruminal, com os seus respectivos erros-padrão, são apresentados na Tabela 6 e na Figura 1. 
Uma generalização comum é que o pH abaixo de 6 inibe a degradação da celulose. Em condições normais, os microrganismos celulolíticos crescem bem em pH de 6,7, de modo que desvios substanciais para elevar ou diminuir esse valor são inibitórios. Uma variação de $\mathrm{pH}$ em que a atividade poderia manter-se próxima do normal seria de 0,5 unidades. Valores de pH inferiores a 6,2 inibem a taxa de digestão e aumentam o lag time para a degradação da parede celular (Van Soest, 1994). Os valores de $\mathrm{pH}$ ruminal obtidos nesse experimento $(5,93$ a 6,47$)$ foram próximos aos sugeridos por Van Soest (1994) e Hoover (1986), o qual afirma que a digestão ruminal da fibra sofre redução em valores de $\mathrm{pH}$ abaixo de 6 , considerando a faixa de 6,2 a 7,0 ideal para digestão da fibra.

Pereira (2003), trabalhando com vacas no terço inicial da lactação alimentadas com dietas à base de farelo de soja, fubá de milho e silagem de milho (15,5\% de PB na MS total), observou valores de $\mathrm{pH}(6,48 ; 6,10 ; 6,05$ e 5,88$)$ próximos aos obtidos neste experimento nos intervalos de amostragem de 0,2, 4 e 6 horas após a alimentação, respectivamente.

As maiores concentrações de $\mathrm{N}-\mathrm{NH}_{3}$ com as dietas FS, FA38, FA28 foram observadas 2 horas após a alimentação e, com a dieta FSU, 4 horas após (Figura 1). A concentração de amônia no rúmen é função de suas taxas relativas de entrada e remoção (Nolan, 1993). Nesse experimento, as concentrações de $\mathrm{N}^{-\mathrm{NH}_{3}}$ variaram de 6,27 a $25,75 \mathrm{mg} / \mathrm{dL}$ nos intervalos de 0 e 4 horas após a alimentação, respectivamente. Estes valores situaram (2 horas pós-alimentação) na faixa

Tabela 6 - Média e erro-padrão da média para pH e concentração de nitrogênio amoniacal ruminal $\left(\mathrm{N}^{-\mathrm{NH}_{3}}\right)$ em função das dietas avaliadas e dos tempos após a alimentação

Table 6 - Average and standard error of mean for ruminal $\mathrm{pH}$ and ruminal ammonia nitrogen concentration $\left(\mathrm{NH}_{3}-\mathrm{N}\right)$ of diets supplemented with different protein sources

\begin{tabular}{lcccc}
\hline Tempo (h) & \multicolumn{5}{c}{$\begin{array}{c}\text { Dieta } \\
\text { Diet }\end{array}$} \\
\cline { 2 - 5 } & \multicolumn{5}{c}{} \\
& FS & FA38 & FA28 & FSU \\
& SBM & CSM38 & CSM28 & SBMU \\
\hline
\end{tabular}

$\mathrm{pH}$ ruminal

$\begin{array}{rrrrr}0 & 6,43 \pm 0,15 & 6,47 \pm 0,09 & 6,43 \pm 0,13 & 6,47 \pm 0,17 \\ 2 & 6,00 \pm 0,15 & 6,10 \pm 0,10 & 6,23 \pm 0,13 & 6,30 \pm 0,10 \\ 4 & 5,93 \pm 0,19 & 5,93 \pm 0,12 & 6,13 \pm 0,09 & 6,20 \pm 0,00 \\ & & \mathrm{NH}_{3}-\mathrm{N}(\mathrm{mg} / \mathrm{dL}) \\ 0 & 6,95 \pm 0,48 & 6,27 \pm 0,90 & 7,70 \pm 1,55 & 6,54 \pm 0,94 \\ 2 & 23,73 \pm 3,52 & 20,65 \pm 5,94 & 21,64 \pm 4,82 & 19,04 \pm 5,07 \\ 4 & 13,97 \pm 2,32 & 13,39 \pm 3,09 & 16,44 \pm 6,37 & 25,75 \pm 9,60\end{array}$

FS = farelo de soja; $F A 38$ = farelo de algodão com $38 \%$ de PB; FA28 = farelo de algodão com $28 \%$ de PB e FSU = FS + uréia (SBM = soybean meal; CSM38 = cottonseed meal with $38 \%$ CP; CSM28 = cottonseed meal with $28 \%$ CP and $S B M U=S B M$ plus urea).

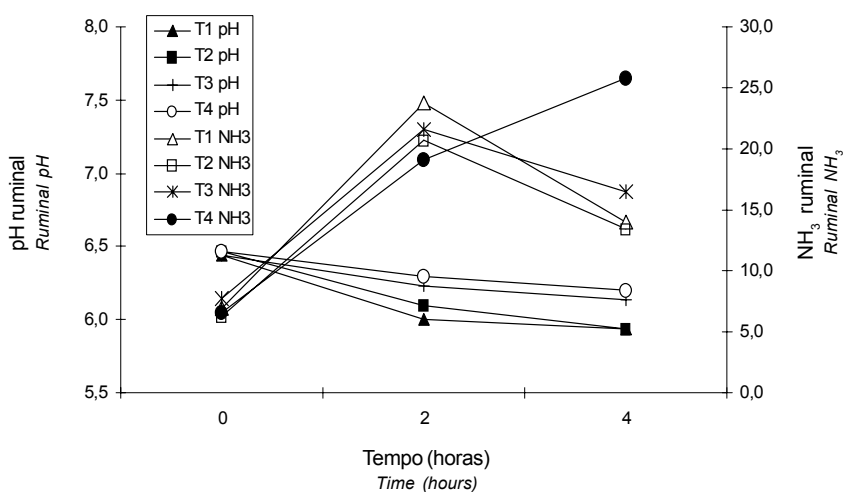

Figura 1 - Efeitos das dietas e dos tempos de amostragem sobre os níveis de $\mathrm{N}-\mathrm{NH}_{3}$ e $\mathrm{pH}$ ruminal.

Figure 1 - Ruminal concentration of $\mathrm{NH}_{3}-\mathrm{N}$ and ruminal $\mathrm{pH}$ ruminal at different times of sampling for each treatments T1 (SBM), T2 (CSM38), T3 (CSM28) e T4 (SBMU).

proposta por Mehrez et al. (1977), que afirmaram que a máxima atividade fermentativa ruminal é obtida quando o $\mathrm{N}-\mathrm{NH}_{3}$ atinge valores de 19 a $23 \mathrm{mg} \mathrm{N} / 100 \mathrm{~mL}$ de líquido ruminal, enquanto, nos demais tempos, situam-se acima do mínimo proposto por Satter \& Slyter (1974), que estabeleceram $5 \mathrm{mg} \mathrm{N}-\mathrm{NH}_{3} / 100 \mathrm{ml}$ de fluido ruminal como suficientes para promover taxas máximas de crescimento microbiano in vitro.

\section{Conclusões}

As concentrações de compostos nitrogenados nãoprotéicos no soro e no leite e a eficiência de síntese de PB microbiana não foram influenciadas pelas diferentes fontes de proteína na dieta, o que sugere a viabilidade da utilização de concentrado contendo $5 \%$ de uréia/sulfato de amônia na MS para animais com produção de $25 \mathrm{~kg}$ de leite/dia alimentados com silagem de milho como volumoso na proporção de $60 \%$ da MS da dieta.

\section{Literatura Citada}

BLACKWELDER J.T.; HOPKINS, B.A.; DIAZ, D.E. et al. Milk production and plasma gossypol of cows fed cottonseed and oilseed meals with or without rumen-undegradable protein.

Journal of Dairy Science, v.81, n.11, p.2934-2941, 1998.

BRODERICK, G.A. Effects of varying dietary protein and energy levelson the production of lactating dairy cows. Journal of Dairy Science, v.86, p.1370-1381, 2003.

BRODERICK, G.A.; CLAYTON, M.K. A statistical evaluation of animal and nutritional factors influencing concentrations of milk urea nitrogen. Journal of Dairy Science, v.80, p.29642971, 1997.

BRODERICK, G.A. Use of milk urea as an indicator of nitrogen utilization in lactating dairy cow. Washington: USDA, Agricultural Research Service; US Dairy Forage Research Center, 1995. 122p. (Research Summaries) 
BUTLER, W.R.; CHERNEY, D.J.R.; ELROD, C.C. Milk urea nitrogen (MUN) analysis: field trial results on conception rates and dietary inputs. In: CORNELL PROCEEDINGS CONFERENCE, 1., 1995. Ithaca. Proceedings... Ithaca: Cornell University, 1995. p.89-95.

CHEN, X.B.; GOMES, M.J. Estimation of microbial protein supply to sheep and cattle based on urinary excretion of purine derivatives - an overview of technical details. Bucksburnd: Rowett Research Institute, 1992. 21p (Occasional publication).

CHIZZOTTI, M.L. Avaliação da casca de algodão para novilhos de origem leiteira e determinação da excreção de creatinina e produção de proteína microbiana em novilhas e vacas leiteiras. Viçosa, MG: Universidade Federal de Viçosa, 2004. 142p. Dissertação (Mestrado em Zootecnia) - Universidade Federal de Viçosa, 2004.

GIESECKE, D.; EHRENTREICH, L.; STANGASSINGER, M. Mammary and renal excretion of purine metabolites in relation to energy intake and milk yield in dairy cows. Journal of Dairy Science, v.77, n.8, p.2376-2381, 1994.

GONDA, H.L.; LINDBERG, J.E. Effect of diet on milk allantoin and its relationship with urinary allantoin in dairy cows. Journal of Dairy Science, v.80, p.364-373, 1997.

GONZÁLEZ-RONQUILLO, M.; BALCELLS, J.; BELENGUER, A. et al. A comparison of purine derivates excretion with conventional methods as indices of microbial yield in dairy cows. Journal of Dairy Science, v.87, n.7, p.2211-2221, 2004.

GONZÁLEZ-RONQUILLO, M.; BALCELLS, J.; GUADA, J.A. et al. Purine derivative excretion in dairy cows: Endogenous excretion and the effect of exogenous nucleic acid supply. Journal of Dairy Science, v.86, n.4, p.1282-1291, 2003.

GRINGS, E.E.; ROFFLER, R.E.; DEITELHOFF, D.P. Response of dairy cows in early lactation to additions of cottonseed meal in alfafa-based diets. Journal of Dairy Science, v.74, p.25802587. 1991.

GUSTAFSSON, A.H.; PALMQUIST, D.L. Diurnal variation of rumen ammonia, serum urea, and milk urea in dairy cows at high and low yields. Journal of Dairy Science, v.76, n.2, p.475-484, 1993.

HOF, G.; VERVOORN, M.D.; LENAERS, P. J. et al. Milk urea nitrogen as a tool to monitor the protein nutrition of dairy cows. Journal of Dairy Science, v.80, n.12, p.3333-3340, 1997.

HOOVER, W.H. Chemical factors involved in ruminal fiber digestion. Journal of Dairy Science, v.69, n.10, p.2755-2766, 1986.

IMAIZUMI, H.; SANTOS, F.A.P.; VOLTOLINI, T.V. et al. Utilização de farelo de algodão como substituto do farelo de soja em dietas para vacas holandesas em lactação. In: REUNIÃO ANUAL DA SOCIEDADE BRASILEIRA DE ZOOTECNIA, 39., 2002, Recife. Anais... Recife: Sociedade Brasileira de Zootecnia, 2002. (CD-ROM)

IPARRAGUERRE, I.R.; CLARK, J.H. Impacts of the sources and amount of crude protein on the intestinal supply of nitrogen fractions and performance of dairy cows. Journal of Dairy Science, v.88, p.E22-E37, 2005 (E. Suppl).

JONKER, J.S.; KOHN, R.A.; ERDMAN, R.A. Milk urea nitrogen target concentrations for lactating dairy cows fed according to national research council recommendations. Journal of Dairy Science, v. 82, n.6, p.1261-1273, 1999.

MEHREZ, A.Z.; ØRSKOV, E.R.; McDONALD, I. Rates of rumen fermentation in relation to ammonia concentration. British Journal of Nutrition, v.38, n.3, p.437-443, 1977.

MENA, H.; SANTOS, J.E.P.; HUBER, J.T. et al. The effects of varying gossypol intake from whole cottonseed and cottonseed meal on lactation and blood parameters in lactating dairy cows. Journal of Dairy Science, v.87, n.8, p.2506-2518, 2004.
MOSCARDINI, S.; WRIGHT, T.C.; LUIMES, P.H. et al. Effects of rumen undegradable protein and feed intake on purine derivative and urea nitrogen: comparison with predictions from the Cornell Net Carbohydrate and Protein System. Journal of Dairy Science, v. 81, n.9, p.2421-2429, 1998.

NOLAN, J.V. Nitrogen metabolism by ruminal microorganisms: current understanding and future perspectives. Australian Journal of Agricultural Research, v.47, p.227-246, 1993.

NOUSIAINEN, J.; SHINGFIEL, K.J.; HUHTANEN, P. et al. Evaluation of milk urea nitrogen as a diagnostic of protein feeding. Journal of Dairy Science, v.87, n.2, p.386-398, 2004.

OLIVEIRA, A.S.; VALADARES, R.F.D.; VALADARES FILHO, S.C. et al. Produção de proteína microbiana e estimativas da excreção de derivados de purinas e de uréia em vacas lactantes alimentadas com rações isoprotéicas contendo diferentes níveis de compostos nitrogenados não protéicos. Revista Brasileira de Zootecnia, v.30, n.5, p.1621-1629, 2001.

PEREIRA, M.L.A. Proteína nas dietas de vacas nos terços inicial e médio da lactação. Viçosa, MG: Universidade Federal de Viçosa, 2003. 105p. Tese (Doutorado em Zootecnia) Universidade Federal de Viçosa, 2003.

PEREIRA, M.L.A.; VALADARES FILHO, S.C.; VALADARES, R.F.D. et al. Consumo, digestibilidade aparente total, produção e composição do leite em vacas no terço inicial da lactação alimentadas com níveis crescentes de proteína bruta no concentrado. Revista Brasileira de Zootecnia, v. 34 , n.3, p. 1029-1039, 2005

PINA, D.S. Fontes de proteína para vacas em lactação Viçosa: Universidade Federal de Viçosa, 2003. 61p. Dissertação (Mestrado em Zootecnia) - Universidade Federal de Viçosa, 2005.

SATTER, L.D.; SLYTER, L.L. Effect of ammonia concentration on rumen microbial protein production in vitro. The British Journal of Nutrition, v.32, n.2, p.199-209, 1974.

SCHEPERS, A.J.; MEIJER, R.G.M. Evaluation of the utilization of dietary nitrogen by dairy cows based on milk concentration in milk. Journal of Dairy Science, v.81, n.2, p.579-584, 1998

SILVA, R.M.N.; VALADARES, R.F.D.; VALADARES FILHO, S.C. et al. Uréia para vacas em lactação. 2. Estimativas do volume urinário, da produção microbiana e da excreção de uréia. Revista Brasileira de Zootecnia, v.30, n.6, p.1948-1957, 2001

VAGNONI, D.B.; BRODERICK, G.A.; CLAYTON, M.K. et al. Excretion of purine derivatives by holstein cows abomasally infused with incremental amounts of purines. Journal of Dairy Science, v. 80, p.1695-1702, 1997.

VALADARES, R.F.D.; GONÇALVES, L.C.; RODRIGUEZ, N.M. et al. Níveis de proteína em dietas de bovinos. 4. Concentrações de amônia ruminal e uréia plasmática e excreções de uréia e creatinina. Revista Brasileira de Zootecnia, v.26, n.6, p.1270-1278, 1997 .

VALADARES, R.F.D.; BRODERICK, G.A.; VALADARES FILHO, S.C. et al. Effect of replacing alfalfa silage with high moisture corn on ruminal protein synthesis estimated from excretion of total purine derivatives. Journal of Dairy Science, v.82, p.2686-2696, 1999

Van SOEST, P.J. Nutritional ecology of the ruminant. 2.ed. London: Constock Publishing Associates, 1994. 476p.

VERBIC, J.; CHEN, X.B.; MACLEOD, N.A. et al. Excretion of purine derivatives by ruminants. Effect of microbial nucleic acid infusion on purine derivative excretion by steers. Journal of Agricultural Science, v.114, n.3, p.243-248, 1990

Recebido: 03/08/05 Aprovado: 30/01/06 